\title{
High-Rate Capability Silicon Decorated Vertically AlignedCarbon Nanotubes for Li-Ion Batteries
}

\author{
Aurélien Gohier*, Barbara Laïk, ${ }^{* \star}$ Ki-Hwan Kim*, Jean-Luc Maurice*, Jean-Pierre \\ Pereira-Ramos**, Costel Sorin Cojocaru*, Pierre Tran Van ${ }^{\star \star \star}$
}

*Laboratoire de Physique des Interfaces et des Couches Minces

LPICM, École Polytechnique, route de Saclay,

91128 Palaiseau Cedex, France

**Institut de Chimie et des Matériaux Paris-Est

ICMPE/GESMAT, UMR 7182 CNRS-UPEC,

2 rue Henri Dunant, 94320 Thiais, France

***Renault SAS, DREAM/DETA/SEE, 1, avenue du Golf, 78288 Guyancourt, France

DOI: 10.1002/adma.201104923

Due to their high energy density, lithium-ion batteries have become a leading technology for medical and electronic devices as well as electric vehicles. The increasing demand for extended autonomy has driven intense research on improved lithium- ion based electrochemical systems. One way to increase battery energy is to maximize the specific capacity. Concerning negative electrode, silicon material is very attractive since it exhibits the highest specific capacity (3580 $\mathrm{mAh} \mathrm{g}^{-1}$ at room temperature), which is about ten times higher than graphitic carbon, used in commercial application. However, during charge i.e. reduction step, lithium/silicon alloying yields very high volume expansion, up to $300 \%$, that induces high mechanical stress. As a result, silicon can fracture leading to significant capacity fading. ${ }^{[1]}$

Then, as nanotechnology develops, various Si-nanostructures have emerged as an appropriate alternative for better accommodating these important volume changes. ${ }^{[2-17]}$ Among the different systems considered, the study of Silicon NanoWires (SiNWs) directly grown on collector has begun only a few years ago. ${ }^{[16,17]}$ Due to excellent electrical connection between SiNWs and the current collector, improved kinetics of lithium ion trans- port and facile strain relaxation, they exhibited improved cycling performance: accessible capacities values, about $3500 \mathrm{mAh} \mathrm{g}^{-1}$ at $\mathrm{C} / 20$ during the second charge, ${ }^{[16]}$ close to theoretical one and little capacity fading up to 10 cycles appeared then as a con- siderable improvement. ${ }^{[16,17]}$ However, capacities are found to decrease rapidly after few tens of cycles, whereas lithium ion electrode materials require higher cyclability and long cycle life. New electrode architectures consisting of silicon and carbon have been proposed to circum- vent these limitations. In that case the use of these two different materials aims to capitalize the respective electrochemical and physical properties of each component. ${ }^{[18-26]}$ Some of them well illustrate the major breakthroughs. Cui and coll. Depositedsilicon nanowires by Chemical Vapor Deposition (CVD) onto carbon nanofibers network $^{[18]}$ to benefit from both the attractive electrochemical performance of silicon and the carbon proper- ties like more efficient electron transport pathways and stable mechanical support. Capacities as high as $2000 \mathrm{mAh} \mathrm{g}^{-1}$ are still available after 30 cycles at C/5 with a rapid increase of coulombic efficiency from 90 to $99.5 \%$ in few cycles. Another alter- native concept suggests the use of an amorphous Si film infiltrated by a Carbon Nanotube
(CNT) network. ${ }^{[27]}$ Once again, the infiltrated CNT network acts as both mechanical support and electrical conductor and silicon as high capacity anode material. Specific charge storage capacity about $2000 \mathrm{mAh} \mathrm{g}^{-1}$ is available and stable after one hundred cycles at a $\mathrm{C} / 3$ rate.

Kumta's team has worked on an hybrid structure made of silicon/carbon nanotubes, exploiting the combined merits of carbon and silicon. ${ }^{[23,28]}$ At first, electrochemical tests were carried out with a composite electrode made of scrapped off silicon/CNTs, acetylene carbon black and binder. ${ }^{[28]}$ Capacities about $1000 \mathrm{mAh} \mathrm{g}^{-1}$ are reached after 100 cycles but at a very slow rate of $\mathrm{C} / 42$. More recently, the same silicon/CNTs anode material has been directly grown at the surface of the current collector. In that case values of 800 $\mathrm{mAh} \mathrm{g}^{-1}$ are obtained at $\mathrm{C} / 10 .{ }^{[23]}$ Even when these preliminary results were obtained for a limited number of cycles and low $\mathrm{C}$ rates, they outline the interest of such a hierarchical structure made of carbon nano- tubes covered with silicon nanoparticles with diameter size of 20 and $60 \mathrm{~nm}$ respectively.

Recently our group demonstrated the crucial impact of the diameter size and distribution on the rate capability of SiNWs grown by HF-CVD showing that the lower the diameter, the better the capacity and the rate capability. ${ }^{[29]}$ Here we report vertically aligned carbon nanotubes decorated with silicon par- ticles (VA-CNTs/Si) arrays with minimized diameter size, 5 and $10 \mathrm{~nm}$ respectively, allowing the best rate capability ever reached for nanostructured Si anodes. A homogeneous disper- sion of $\mathrm{Si}$ nanoparticles along thin CNTs allows optimizing the electrochemical efficiency of Si, CNTs ensuring an excellent electronic conduction. As a result, we present excellent elec- trochemical performance at high rate, up to $15 \mathrm{C}$ for VA-CNTs arrays directly grown onto metal foils and then decorated with silicon nanoparticles.

SEM pictures of the resulting structure at various magnifications are displayed in Figure 1a-c. The deposit exhibits a carpet of highly packed oriented carbon nanotubes with a height of $11 \mu \mathrm{m}$ (inter-CNTs distance was $\sim 50 \mathrm{~nm}$ ) (Figure 1a and b). Each carbon nanotube is perpendicular to the substrate (Ver- tically Aligned-Carbon NanoTube: VA-CNT) and covered by well defined Si nanoparticles (Figure $1 \mathrm{~b}$ and c). We think that 


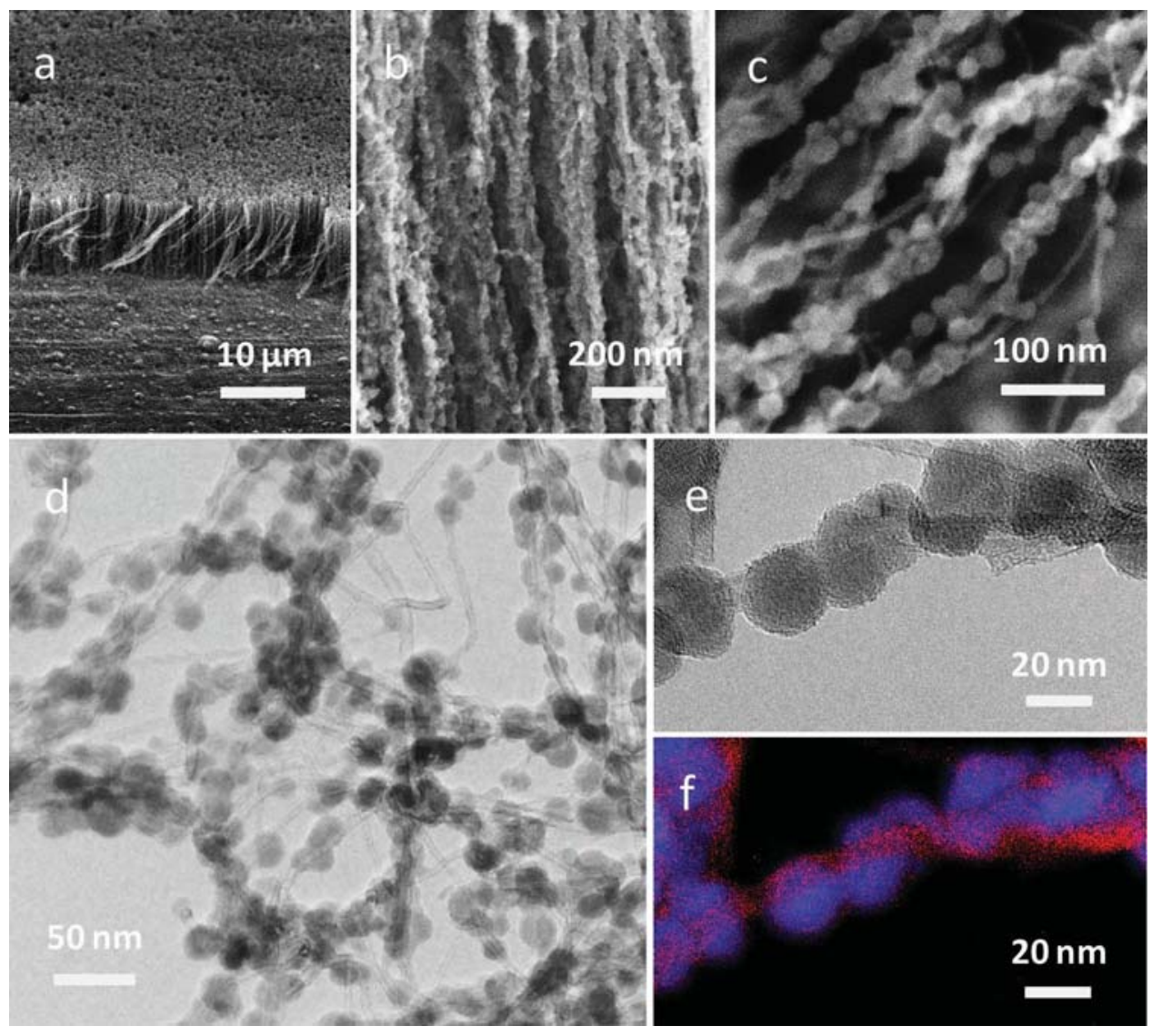

Figure 1. a-c) SEM images of VA-CNTs/Si structure. d) Low magnification and e) High magnification TEM picture of VA-CNTs/Si structure. f) Carbon (red) and silicon (blue) map of a Si decorated CNT using energy spatially resolved energy-filtered TEM.

during the early stage of the second CVD process step, silicon precursor preferentially sticks onto CNTs structural defects and create silicon-based seeds onto which silicon particles are further formed by isotropic growth.

Figure 1d displays a low magnification TEM image of hybrid VA-CNTs/Si structure. VA-CNTs and silicon particles exhibit a mean diameter of $\sim 5 \mathrm{~nm}$ and $\sim 10-20 \mathrm{~nm}$ respectively. Hence the CNT matrix as well as the Si particles have here a significantly lower diameter size of 5 and 10-20 nm against respectively 20 and $60 \mathrm{~nm}$ for CNTs and Si previously reported in VACNTs. ${ }^{[23]}$ These particular nanosized components of the hybrid electrode have been reached using experimental conditions quite different from those applied in ref. [23]. For instance, some applied parameters differ like the catalyst for CNTs growth, the temperatures for CNTs and silicon synthesis and the flowing gas for Si deposit. As a consequence of these really nanosized CNTs and Si particles, a high surface electrochemical area can be expected with new properties.

Figures 1e and f are energy-filtered TEM (EFTEM) images. They show respectively a zero-loss and carbon/silicon map of an individual Si-decorated CNT that confirm the nature of the hybrid structure.

Figure 2 shows a Selected Area Electron Diffraction pattern (SAED) recorded over a large sample area, clearly exhibiting

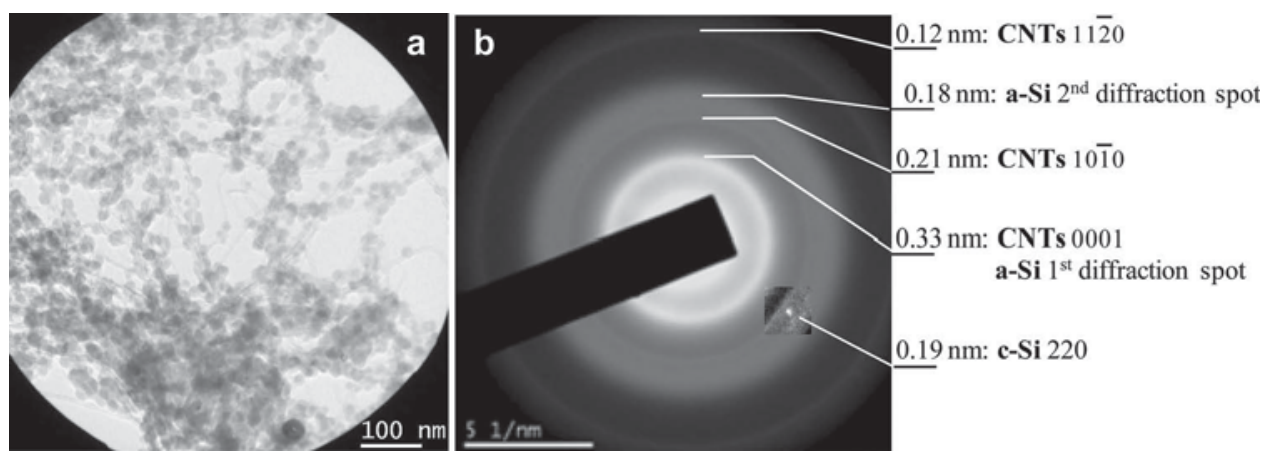

Figure 2. a) Area of sample selected for diffraction and b) EDP from that area. 

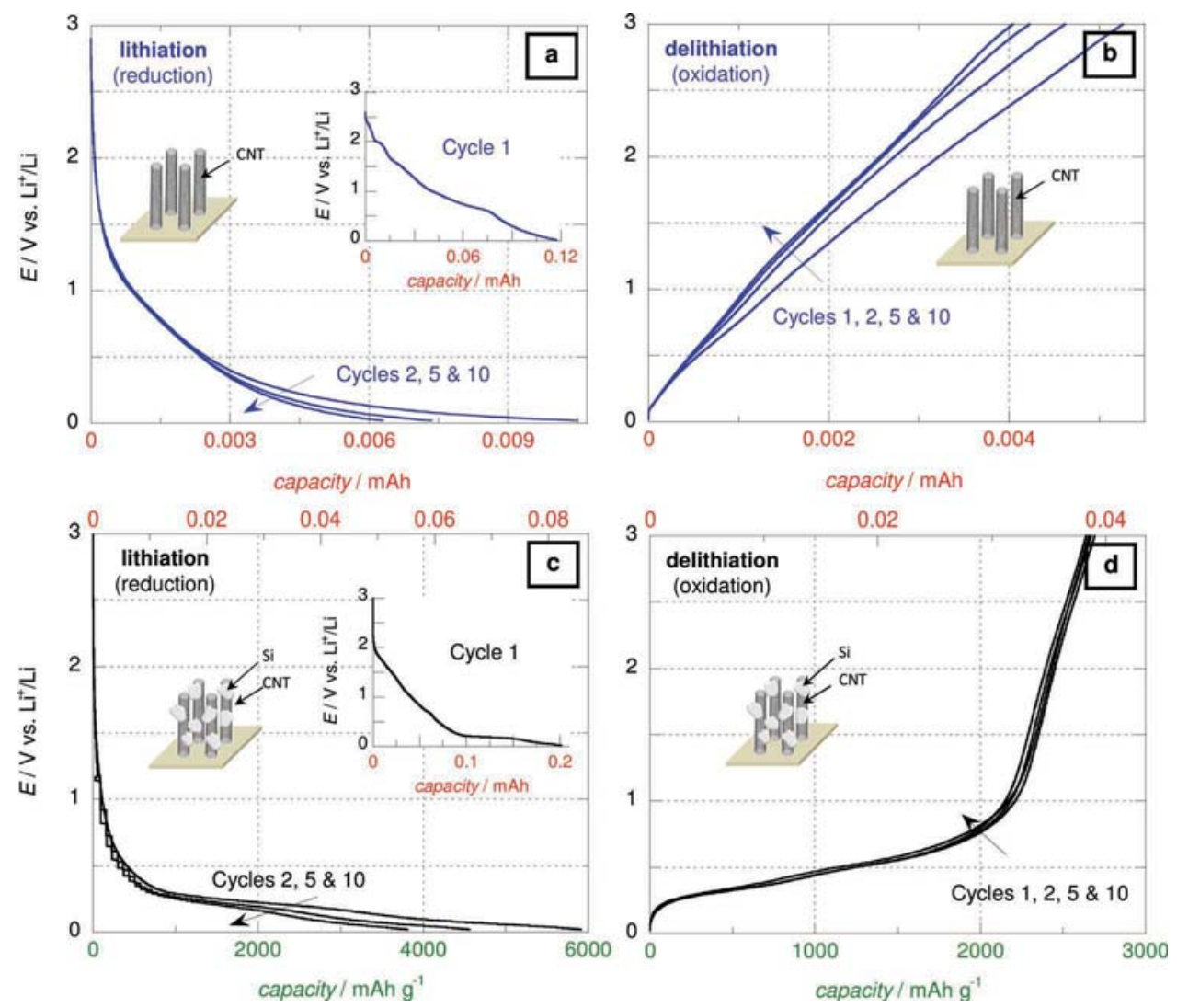

Figure 3. Galvanostatic profiles at $1.3 \mathrm{C}$ in the potential window $3 \mathrm{~V}-0.02 \mathrm{Vvs} \mathrm{Li} / \mathrm{Li}$ for the $1^{\text {st }}, 2^{\text {nd }}, 5^{\text {th }}$ and $10^{\text {th }}$ cycles of a) b) VA-CNTs sample and c) d) VA-CNTs/Si electrode. For comparison, capacities involved in VA-CNTs a) b) and VA-CNTs/Si c) d) are expressed in mAh. The lithiation and delithiation capacities for the VA-CNTs/Si c) d) are reported in $\mathrm{mAh}^{-1}$ of silicon (bottom scale).

rings typical, on the one hand, of mainly amorphous silicon ${ }^{[30,31]}$ and, on the other hand, of the carbon nanotubes. Very few individual spots sometimes appear, like that visible with contrast enhancement in Figure 2b. Those spots belong to small silicon areas that are crystallized.

Before testing VA-CNTs/Si as active electrode material against Li alloying, we have evaluated the electrochemical contribution of carbon nanotubes, by cycling a VA-CNTs sample without silicon. Experimental conditions have been chosen so that it surface $\left(10 \mathrm{~mm}^{2}\right)$ and the galvanostatic current density $\left(0.77 \mathrm{~mA} \mathrm{~cm}^{-2}=1.3 \mathrm{C}\right.$ rate) were the same applied for VA$\mathrm{CNTs} / \mathrm{Si}$ electrodes. Figures 3a and b show the voltage profiles of cycles 1 (reduction step in inset), 2, 5 and 10. During the first cycle, the capacities reach $0.12 \mathrm{mAh}$ but only $0.005 \mathrm{mAh}$ for charge (lithiation) and discharge (delithiation) respectively, showing the poor rechargeability of CNTs. The shape of the reduction curve is typical of Solid Electrolyte Interface (SEI) formation onto carbon nanotubes, in good agreement with literature data on CNTs electrochemistry. ${ }^{[32-34]}$ From the second cycle, the charge capacity dramatically and continuously drops. In fact CNTs directly deposited on current collector lead to a residual capacity which never exceeds a few $\mu$ Ah after a few cycles.

Figures 3c and d are related to a VA-CNTs/Si electrode cycled between $3 \mathrm{~V}$ and $20 \mathrm{mV}$ vs $\mathrm{Li}^{+} / \mathrm{Li}$, at $1.3 \mathrm{C}$ rate. Capacities are expressed, like for VA-CNTs without silicon, in mAh for an easier comparison (scale of the top). During the first reduction, a high capacity of $0.20 \mathrm{mAh}$ is achieved. The curve splits into two parts: half the capacity recovered between $2 \mathrm{~V}$ and $0.2 \mathrm{~V}$ vs $\mathrm{Li}^{+} / \mathrm{Li}$ corresponding to the SEI formation and half to the lithium alloying process that is characterized by a voltage plateau at $200 \mathrm{mV}$. In good agreement with previous studies, ${ }^{[14,35]}$ this potential corresponds to the alloying process in amorphous silicon of which our samples are made of as shown by SAED analysis. Considering now the first oxidation and the following cycles, the curves shape well reflects the delithiation mechanism $^{[35]}$ involving two steps at $\sim 300 \mathrm{mV}$ and $\sim 500 \mathrm{mV}$. Capacities involved with VA-CNTs/Si electrode are ten-fold that observed for pure CNTs. It can be then considered in the following of the study that the whole specific capacity is related to silicon alloying/dealloying.

In addition, Figure 3d shows that the silicon particles contribution (scale of bottom) is remarkably stable at $2600 \mathrm{mAh} \mathrm{g}^{-1}$ whatever the cycle while a strong decrease of the charge capacity (lithiation) occurs in the first ten cycles. At cycle 10, charge and discharge profiles show specific capacities of $3760 \mathrm{mAh} \mathrm{g}^{-1}$ and $2650 \mathrm{mAh} \mathrm{g}^{-1}$, respectively. The lithium alloying/dealloying process into silicon nanoparticles combined with the mechanical and electrical carbon properties are shown to provide a large capacity at relatively high rate $(1.3 \mathrm{C})$. 

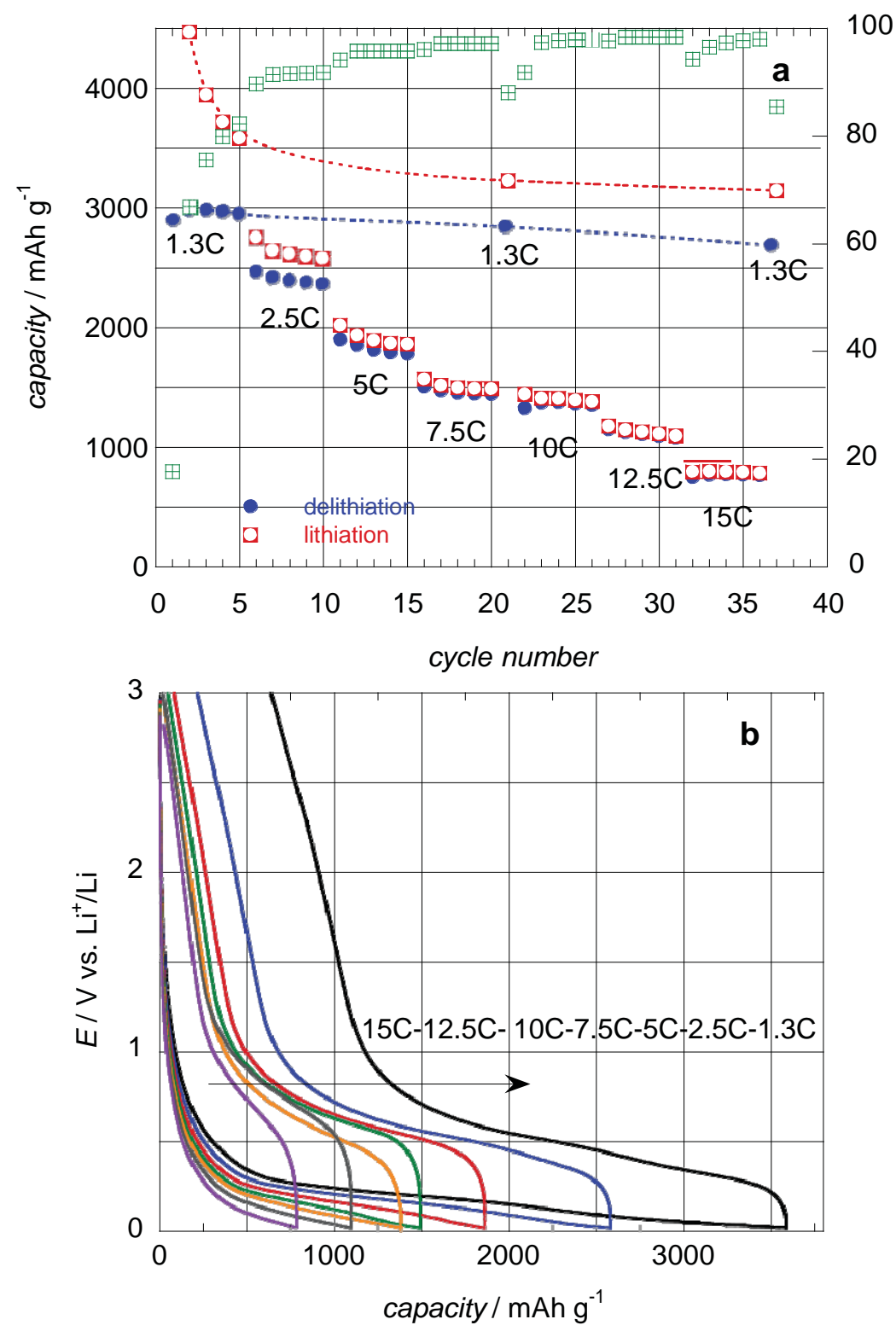

Figure 4. Rate capabilities of VA-CNTs/Si electrode. a) Charge/discharge specific capacities at various rates, from $1.3 \mathrm{C}$ to $15 \mathrm{C}$. b) Galvanostatic profiles recorded at $1.3 \mathrm{C}, 2.5 \mathrm{C}, 5 \mathrm{C}, 7.5 \mathrm{C}$, $10 \mathrm{C}, 12.5 \mathrm{C}$ and $15 \mathrm{C}$.

In order to investigate higher rate for VA-CNTs/Si electrodes, galvanostatic measurements were performed at various rates, from $1.3 \mathrm{C}$ to $15 \mathrm{C}$. Figure 4 displays the specific capacities obtained as a function of the lithiation/delithiation rate. The discharge (Li dealloying) capacities at these rates are 2980, 2440, 1890, 1470, and 1360, 1100, and $765 \mathrm{mAh} \mathrm{g}^{-1}$, for $1.3 \mathrm{C}$, $2.5 \mathrm{C}$, 5 C, 7.5 C, 10 C, 12.5 C, and 15 C, respectively. Depending on the $\mathrm{C}$ rate, the VA-CNTs/Si capacities are found to be 2 up to 8 -fold higher than the practical capacity achieved with graphite. These outstanding rechargeable capacities well exemplify the high rate behavior allowed with these specific hierarchical hybrid nanostructures. Indeed, the best results known from the literature for analog hybrid material, but used in composite electrode $^{[28]}$ are low with about $2000 \mathrm{mAh} \mathrm{g}^{-1}$ but at $\mathrm{C} / 42$ rate (full lithiation in $42 \mathrm{~h}$, i.e., one electron per 10 hours). We obtain here equivalent values for largely higher rate, namely about $5 \mathrm{C}$, that confirms the real potentiality of as prepared hybrid silicon/carbon material.

The large irreversible capacity found in cycle 1 is due to the large surface area of CNTs and Si nanoparticles. For further cycles (Figure 4a), this irreversible capacity rapidly decreases. The systematic higher lithiation capacity compared to the previous delithiation one is clearly ascribed to the SEI formation on $\mathrm{Si}$ nanoparticles, the discharge capacity (oxidation) of $3000 \mathrm{mAh} \mathrm{g}^{-1}$ being constant with cycles. This value is directly connected to the amount of lithium alloyed with silicon. In addition to the attractive capacity values, the coulombic efficiency significantly increases with the applied current density. Indeed it changes from $85 \%$ at $1.3 \mathrm{C}$ to $98 \%$ at $15 \mathrm{C}$. This finding is consistent with the trend reported for various kinds of Si-nanostructured anodes. ${ }^{[16,35-37]}$ Such an improvement of the coulombic efficiency can be explained by high rates that promote the Si-alloying process at the expense of the SEI formation for kinetic reasons and by a limited alloying process inducing a minimized silicon volumetric expansion. As a result, cracks are limited and SEI is more stable. A salient point is that high cycling rate (up to $15 \mathrm{C}$ ) does not damage the further electrode performance as the available capacity recovered at $1.3 \mathrm{C}$ does not significantly change (Figure 4a). These results show that the prepared material is well adapted for high rate application.

The corresponding voltage profiles (Figure 4b) clearly show the working potentials between the mid charge and mid discharge are not greatly affected $(\leq 150 \mathrm{mV})$, in spite of a $\mathrm{C}$ rate increasing by one order of magnitude from $1.3 \mathrm{C}$ to $15 \mathrm{C}$. This exemplifies the excellent electron transport to and from silicon nanoparticles ensured by CNTs directly connected to the current collector. Also the highly porous character of this hierarchical combination of nanostructures and the short diffusion pathway for Li in nanosized Si particles probably favor a fast and homogeneous electrochemical process with a minimization of the structural stress leading to a high rechargeability at high rates.

In order to confirm the ability of this hybrid anode material to work at high rate, VA-CNTs/Si electrode cyclability has been investigated upon 100 cycles and the evolution of the specific capacities is displayed in Figure 5. Three cycles were first performed at $1.3 \mathrm{C}$ and then 97 cycles at $10 \mathrm{C}$. The first cycle at $10 \mathrm{C}$ shows charge and discharge capacity of $1616 \mathrm{mAh} \mathrm{g}^{-1}$ and $1400 \mathrm{mAh} \mathrm{g}^{-1}$ respectively and a coulombic efficiency of $87 \%$. The coulombic efficiency rapidly stabilizes at $\sim 94 \%$. The capacity at first drops and reaches $1168 \mathrm{mAh} \mathrm{g}^{-1}$ at cycle 14 . 


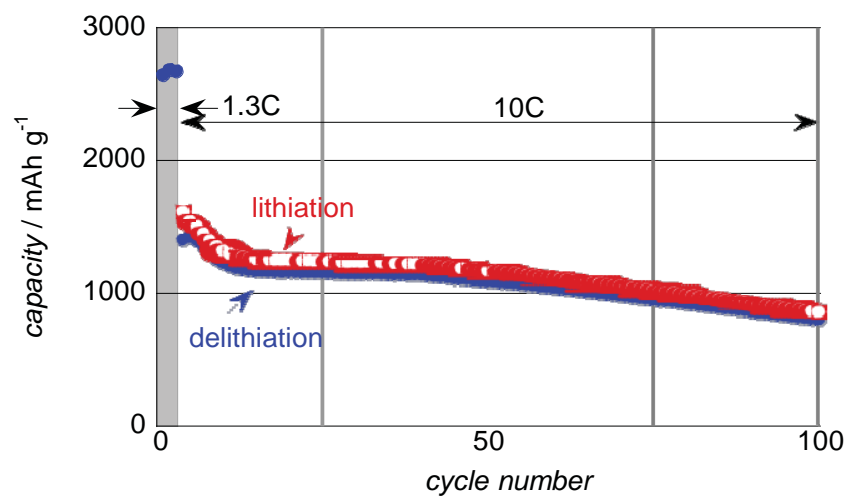

Figure 5. Cyclability of VA-CNTs/Si electrode, between $3 \mathrm{~V}-0.02 \mathrm{~V}$ vs. $\mathrm{Li}^{+} / \mathrm{Li}$, at $10 \mathrm{C}$ upon 100 cycles.

Then, the capacity stabilizes up to cycle 40 ( $0.1 \%$ loss per cycle). From cycle 40 to cycle 100 , a slow and continuous capacity fading is observed but a high capacity value, $800 \mathrm{mAh} \mathrm{g}^{-1}$, is still recovered at cycle 100 .

Our results at $10 \mathrm{C}$ after 100 cycles overpass that obtained from the various approaches developed to benefit from the attractive properties of silicon deposit directly grown on the current collector: SiNWs, ${ }^{[16]}$ interconnected SiNWs, ${ }^{[36]}$ crystallineamorphous core-shell SiNWs, ${ }^{[14]} \mathrm{Si} / \mathrm{TiC} / \mathrm{C}$ nanofiber scaffold $^{[38]}$ and Si decorated VA-CNTs. ${ }^{[23]}$ Indeed, the latter report usual maximum $\mathrm{C}$ rates of $2 \mathrm{C}$ with capacities varying from $800 \mathrm{mAh}^{-1[14]}$ to $1500 \mathrm{mAh} \mathrm{g}^{-1[6]}$ and exceptionally $8 \mathrm{C}$ with capacities about $400 \mathrm{mAh} \mathrm{g}^{-1} \cdot{ }^{[36]}$

In conclusion we report the electrochemical characterization of silicon decorated vertically aligned carbon nanotubes directly grown onto metal foil via a two-step CVD process. This specific hierarchical hybrid nanostructure is made of very thin CNTs $5 \mathrm{~nm}$ in diameter on which $10 \mathrm{~nm}$ Si nanoparticles homogeneously deposited are responsible for the high reversible Li storage capacity of $3000 \mathrm{mAh} \mathrm{g}^{-1}$ at $1.3 \mathrm{C}$. Such a VACNTs electrode exhibits an impressive rate capability: a capacity of $1900 \mathrm{mAh} \mathrm{g}^{-1}$ is achieved at $5 \mathrm{C}$ and $760 \mathrm{mAh} \mathrm{g}^{-1}$ at $15 \mathrm{C}$ which is the best one ever reported for a silicon-based electrode including previous VA-CNTs, SiNWs, various nanostructured Si anode materials, composite electrodes, etc $\cdots$ The present VA$\mathrm{CNTs} / \mathrm{Si}$ are found to sustain very high $\mathrm{C}$ rates without any significant polarization and without structural damaging. Cycling at $10 \mathrm{C}$ leads to a recovered capacity of $800 \mathrm{mAh} \mathrm{g}^{-1}$, i.e. still two times the capacity of graphite. The key factors for good cycling properties are the perfect adhesion between CNTs directly connected to the current collector and silicon particles thus facilitating electron and lithium ion transport pathway and limiting the diffusion process occurring in conventional electrodes. Our results suggest the VA-CNTs/Si are effective for overcoming the effects of volume expansion-contraction and represent a promising direction for use in practical cells.

\section{Experimental Section}

The fabrication of the VA-CNTs/Si electrode was performed using a twostep Chemical Vapor Deposition process: i) growth of VA-CNTs onto stainless steel foils ii) VA-CNTs decoration with silicon particles.
At first, Vertically Aligned Carbon NanoTubes were synthesized by Hot-Filament Chemical Vapour Deposition (HF-CVD) on $50 \mu \mathrm{m}$ thick stainless steel foils (Aldrich, AISI 321) as previously described in detail. ${ }^{[39]}$ Steel substrates were copiously washed with acetone and isopropanol and then covered by an aluminum buffer layer $(20 \mathrm{~nm})$ deposited by e-beam evaporation technique. Iron chloride used here as catalyst precursor for CNT growth was deposited by spraying $30 \mathrm{~mL} \mathrm{FeCl}_{3}, 6 \mathrm{H}_{2} \mathrm{O}$ solution $\left(5.10^{-4} \mathrm{~mol} \mathrm{~L}^{-1}\right.$ in ethanol) over the foil heated at $120{ }^{\circ} \mathrm{C}$. From as-deposited iron chloride salt, CNTs synthesis was performed at $600{ }^{\circ} \mathrm{C}$ using $\mathrm{CH}_{4} / \mathrm{H}_{2}$ mixture $\left(\Phi_{\mathrm{H} 2}=100 \mathrm{sccm}, \Phi_{\mathrm{SiH} 4}=20 \mathrm{sccm}\right)$ during 30 minutes. The pressure was set at 50 mbar and the tungsten filament power at $205 \mathrm{~W}$. Secondly, VA-CNTs silicon decoration was performed by CVD using $\mathrm{SiH}_{4} / \mathrm{H}_{2}$ mixture $\left(\Phi_{\mathrm{H} 2}=100 \mathrm{sccm}, \Phi_{\mathrm{SiH} 4}=20 \mathrm{sccm}\right)$ at $540{ }^{\circ} \mathrm{C}$. The pressure was set at 50 mbar and synthesis duration at 13 minutes. The mass of deposited silicon is determined by weighing measurements using a quartz crystal microbalance before and after Si deposit on a $3 \mathrm{~cm}^{2}$ VA-NTCs covered sample and is about $0.17 \mathrm{mg} \mathrm{cm}^{-2}$.

Morphological characterization of VA-CNTs/Si samples was investigated by SEM (SEM; HITACHI S 4800) and transmission electron microscopy (TEM; Jeol).

Electrochemical studies were carried out in a two-electrode cell (Swagelok type) as described in detail elsewhere. ${ }^{[40]}$ The electrolyte was a commercial solution of $1 \mathrm{~mol} \mathrm{~L}^{-1} \mathrm{LiPF}_{6}$ in dimethylcarbonate (LP30) obtained from Merck. Galvanostatic measurements were recorded with voltage cut-off of $0.02 \mathrm{~V}$ and $3 \mathrm{~V}$ vs $\mathrm{Li}^{+} / \mathrm{Li}$, using VMP3 apparatus (Biologic). A constant current density was used for lithiation/delithiation experiments $\left(1 \mathrm{C}=3.58 \mathrm{Ag}^{-1}\right)$.

\section{Acknowledgements}

This work was partially supported by the "Sustainable Mobility Institute" (Renault/ParisTech).

Received: December 24, 2011

Revised: February 17, 2012

Published online: April 10, 2012

[1] B. A. Boukamp, G. C. Lesh, R. A. Huggins, J. Electrochem. Soc. 1981, $128,725$.

[2] B. Gao, S. Sinha, L. Fleming, O. Zhou, Adv. Mater. 2001, 13, 816

[3] U. Kasavajjula, C. S. Wang, A. J. Appleby, J. Power Sources 2007, 163, 1003.

[4] R. Teki, M. K. Datta, R. Krishnan, T. C. Parker, T. M. Lu, P. N. Kumta, N. Koratkar, Small 2009, 5, 2236.

[5] J. Cho, J. Mater. Chem.2010, 20, 4009.

[6] Y. Yao, M. T. McDowell, I. Ryu, H. Wu, N. A. Liu, L. B. Hu, W. D. Nix, Y. Cui, Nano Lett. 2011, 11, 2949.

[7] M. H. Park, M. G. Kim, J. Joo, K. Kim, J. Kim, S. Ahn, Y. Cui, J. Cho, Nano Lett. 2009, 9, 3844.

[8] E. Ossei-Wusu, A. Cojocaru, H. Hartz, J. Carstensen, H. Föll, Phys. Status Solidi A 2011, 208, 1417.

[9] R. Huang, J. Zhu, Mater. Chem. Phys. 2010, 121, 519.

[10] K. Peng, J. Jie, W. Zhang, S.-T. Lee, Appl. Phys. Lett. 2008, 93, 033105.

[11] L. B. Hu, H. Wu, S. S. Hong, L. F. Cui, J. R. McDonough, S. Bohy, Y. Cui, Chem. Commun. 2011, 47, 367.

[12] Z. S. Wen, M. K. Cheng, J. C. Sun, L. A. Wang, Electrochim. Acta $2010,56,372$.

[13] L. Baggetto, D. Danilov, P. H. L. Notten, Adv. Mater. 2011, 23, 1563.

[14] L. F. Cui, R. Ruffo, C. K. Chan, H. L. Peng, Y. Cui, Nano Lett. 2009, 9, 491.

[15] D. Wang, Z. Yang, F. Li, X. Wang, D. Liu, P. Wang, D. He, Mater. Lett. 2011, 65, 3227. 
[16] C. K. Chan, H. L. Peng, G. Liu, K. Mcllwrath, X. F. Zhang, R. A. Huggins, Y. Cui, Nat. Nanotech. 2008, 3, 31.

[17] B. Laïk, L. Eude, J.-P. Pereira-Ramos, C. S. Cojocaru, D. Pribat, E. Rouvière, Electrochim. Acta 2008, 53, 5528.

[18] L. F. Cui, Y. Yang, C. M. Hsu, Y. Cui, Nano Lett. 2009, 9, 3370.

[19] I. S. Kim, P. N. Kumta, J. Power Sources 2004, 136, 145.

[20] G. K. Simon, B. Maruyama, M. F. Durstock, D. J. Burton, T. Goswami, J. Power Sources 2011, 196, 10254.

[21] S.-H. Ng, J. Wang, D. Wexler, K. Konstantinov, Z.-P. Guo, H.-K. Liu, Angew. Chem. Int. Ed. 2006, 45, 6896.

[22] C. K. Chan, R. N. Patel, M. J. O'Connell, B. A. Korgel, Y. Cui, ACS Nano 2010, 4, 1443.

[23] W. Wang, R. Epur, P. N. Kumta, Electrochem. Commun. 2011, 13, 429.

[24] H. Chen, Z. Dong, Y. Fu, Y. Yang, J. Solid State Electrochem. 2010, 14, 1829.

[25] M. K. Datta, J. Maranchi, S. J. Chung, R. Epur, K. Kadakia, P. Jampani, P. N. Kumta, Electrochim. Acta 2011, 56, 4717.

[26] C. Martin, O. Crosnier, R. Retoux, D. Belanger, D. M. Schleich, T. Brousse, Adv. Funct. Mater. 2011, 21, 3524.

[27] L. F. Cui, L. B. Hu, J. W. Choi, Y. Cui, ACS Nano 2010, 4, 3671.

[28] W. Wang, P. N. Kumta, ACS Nano 2010, 4, 2233.

[29] A. Gohier, B. Laïk, J.-P. Pereira Ramos, C. S. Cojocaru, P. Tran Van, J. Power Sources 2012, 203, 135
[30] A. Uhlherr, S. R. Elliott, J. Non-Cryst. Solids 1995, 193, 98.

[31] M. Cuniot, J. Dixmier, P. R. Cabarrocas, J. Non-Cryst. Solids 1996, $200,540$.

[32] B. J. Landi, M. J. Ganter, C. D. Cress, R. A. DiLeo, R. P. Raffaelle, Energy Environ. Sci. 2009, 2, 638.

[33] J.-X. Li, Y. Zhao, L.-H. Guan, Electrochem. Commun. 2010, 12, 592.

[34] E. Frackowiak, S. Gautier, H. Gaucher, S. Bonnamy, F. Beguin, Carbon 1999, 37, 61.

[35] M. N. Obrovac, L. J. Krause, J. Electrochem. Soc. 2007, 154(2), A103-A108.

[36] H. T. Nguyen, F. Yao, M. R. Zamfir, C. Biswas, K. P. So, Y. H. Lee, S. M. Kim, S. N. Cha, J. M. Kim, D. Pribat, Adv. Energy Mater. 2011, 1,1154 .

[37] T. Takamura, S. Ohara, M. Uehara, J. Suzuki, K. Sekine, J. Power Sources 2004, 129, 96.

[38] Y. Yao, K. Huo, L. Hu, N. Liu, J. J. Cha, M. T. McDowell, P. K. Chu, Y. Cui, ACS Nano 2011, 5, 8346.

[39] A. Gohier, K. H. Kim, E. Norman, L. Gorintin, P. Bondavalli, C. S. Cojocaru, Appl. Surf. Sci. 2012, in press.

[40] B. Laïk, D. Ung, A. Caillard, C. S. Cojocaru, D. Pribat, J.P. Pereira-Ramos, J. Solid State Electrochem. 2009, 14, 1835. 